\title{
Research Paper: Effect of Mindfulness-based Cognitive Therapy on Substance Dependence Intensity and Cognitive Emotion Regulation in Patients Under Methadone Maintenance Treatment
}

\author{
Shokoufeh Ramezani ${ }^{*}$ (D), Abdul Rahim Afkhamzadeh² ${ }^{2}$, Hassan $_{\text {Qorbani }}{ }^{3}$, Salm Naimi $^{4}$, Saifullah Rahmani $^{5}$ \\ 1. Department of Psychology, Faculty of Education and Psychology, University of Mohaghegh Ardabili, Ardabil, Iran. \\ 2. Department of Community Medicine, School of Medicine Social Determinants of Health Research Center Research Institute for Health Development \\ Kurdistan University of Medical Sciences, Kurdistan, Iran. \\ 3. Department of Clinical Psychology, University of Social Welfare and Rehabilitation Science, Tehran, Iran. \\ 4. Department of Clinical Psychology, Faculty of Human sciences, Sanandaj Branch, About Islamic Azad University, Kurdistan, Iran. \\ 5. Department of Educational Sciences, Farhangian University (Pardis Shahid Modares), Kurdistan, Iran.
}

\begin{tabular}{|c|c|}
\hline $\begin{array}{l}\text { Use vour device to scan } \\
\text { and read the article online }\end{array}$ & Crtation: Ramezani, Sh., Afkhamzadeh, A. R., Qorbani, H., Naimi, S, \& Rahmani, S. (2019). Effect of Mindfulness-based \\
\hline 口ipra & $\begin{array}{l}\text { Cognitive Therapy on Substance Dependence Intensity and Cognitive Emotion Regulation in Patients Under Methadone Mainte- } \\
\text { nance Treatmen. Journal of Practice in Clinical Psychology, 7(3), 225-234. http://dx.doi.org/10.32598/jpcp.7.3.225 }\end{array}$ \\
\hline 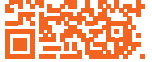 & 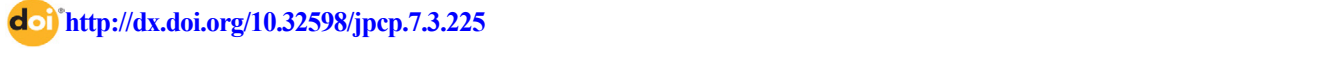 \\
\hline
\end{tabular}

\section{(c) (1) (s)}

Article info:

Received: 22 Jan 2019

Accepted: 03 May 2019

Available Online: 01 Jul 2019

Keywords:

Mindfulness-based cognitive therapy, Intensity of substance dependence, Cognitive therapy, Methadone therapy

\begin{abstract}
A B STRACT
Objective: Substance dependence is the most critical biopsychosocial and legal problem. It has various harmful effects at the individual, familial, and society levels. The current study aimed to determine the effect of mindfulness-based cognitive therapy on reducing the intensity of substance dependence and improving cognitive emotion regulation in substance-dependent patients under methadone maintenance treatment.

Methods: This was a quasi-experimental study with a Pre-test-post-test design and a control group. The samples consisted of 29 subjects (16 in the experimental group and 13 in the control group) undergoing methadone maintenance treatment in a methadone maintenance treatment clinic in Kamyaran, Kurdistan Province, Iran. They were randomly assigned to the experimental and control groups. The experimental group underwent 10 sessions of mindfulness-based cognitive therapy. Dependence Severity Index and Cognitive Emotion Regulation Questionnaire were used for data collection.
\end{abstract}

Results: The obtained results suggested that mindfulness-based cognitive therapy reduced the severity of substance dependence $(\mathrm{F}=2.34, \mathrm{P}<0.05)$, influenced Negative cognitive emotion regulation $(\mathrm{F}=15.28, \mathrm{P}<0.05)$ and Positive cognitive emotion regulation $(\mathrm{F}=16.24, \mathrm{P}<0.05)$

Conclusion: Mindfulness-based cognitive therapy affects the intensity of substance dependence and improves cognitive emotion regulation.

\footnotetext{
* Corresponding Author:

Shokoufeh Ramezani, MA.

Address: Department of Psychology, Faculty of Education and Psychology, University of Mohaghegh Ardabili, Ardabil, Iran. Tel: +98 (919) 0436526

E-mail: lavinramezani@yahoo.com
} 


\section{Highlights}

- Mindfulness-based cognitive therapy reduces the severity of substance dependence.

- Mindfulness-based cognitive therapy improves cognitive emotion regulation in addicts.

\section{Plain Language Summary}

Drug abuse is one of the worst health, mental, social, and legal problems in the world. Therefore, many programs are being developed to prevent and treat it. Alongside arbitration therapies, psychological interventions are undoubtedly needed to treat addiction. One of the psychological interventions is mindfulness-based cognitive therapy. Mindfulness-based cognitive therapy is a type of psycho-educational response that helps individuals to practice mental-physical meditation. One of the psychological variables that should be considered in the treatment of addiction is the decrease in the severity of dependence. Tolerance and dependence are significant problems with drug use. Substance dependence is characterized by frequent substance use and reversible recurrence. Probably the most debilitating consequence of repeated drug use is psychological dependence or addiction. As permanent consumers of materials report that substance use has a positive effect on alleviating their negative affective states, so substance use may serve as a cognitive emotion regulation strategy to reduce distressing emotional states. Mindfulness means paying attention in a specific, purposeful, present-day, and judgment-free way. The results of this study showed that mindfulness-based cognitive therapy had a positive effect on decreasing the severity of dependence and emotional adjustment in methadone-treated addicts.

\section{Introduction}

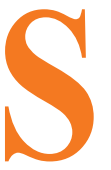

ubstance abuse is among the most important biopsychosocial and legal issues, which negatively affects individuals, families, and societies (Wallace, 2019).

This dilemma not only endangers the health of individuals and society but also causes mental and moral degradation (Green et al., 2018). Overdose, the transmission of infectious diseases and mental health problems are among issues associated with substance use. In terms of society, substance abuse generates criminal and legal issues, collapses families, and reduces productivity (Wallace, 2019).

Several psychoanalytic treatments, behavioral therapy, group therapy, pharmacotherapy, etc. have been conducted on substance-dependent patients; each of these practices has been effective, to some extent and the therapeutic result was the non-recurrence of substance abuse (Bryant \& Veroff, 2017). Mindfulness-Based Cognitive Therapy (MBCT), as a psycho-educational intervention, as well as cognitive-behavioral therapies have gained significant experimental support (Bryant \& Veroff, 2017).

MBCT helps people practice biopsychological meditation. Mindfulness means to pay attention in a particular way, which is purposeful, present-time focused, and non-judgmental (Segal \& Teasdale, 2018). In this pat- tern, mindfulness comprises concentrating the intentional attention on the ongoing experience. Such attention is non-judgmental and accompanied by acceptance (McEE voy, Graville, Hayes, Kane, Foster, 2017). MBCT is associated with acceptance, increased awareness, de-sensitization, the presence at the moment, observing withou judgment, confronting, and releasing. Thus, mindfulness reduces symptoms and the withdrawal signs, increases the effectiveness of treatment, and prevents relapse (Stroes et al., 2015). Garland (2012) argued practicing MBCT is related to the behaviors leading to reduced substance abuse in patients under the treatment.

Another indicator of treatment effect mindfulness is a component of the mind. One-third of depressed people suffer from substance abuse (Davis et al., 2008). Given the importance of creativity in substance dependence treatment, MBCT has been used to improve depression symptoms (Kingston, Dooley, Bates A, Lawlor, Malone, 2007).

Tolerance and dependence are the main problems associated with substance abuse. Dependence on substances is characterized by repeated substance intake and reversible relapse. Probably the most debilitating consequence of repeated substance use is psychological dependence (Marchiafava et al., 2018). Substance dependence can be evaluated by withdrawal Syndrome, which is caused by the increased irritability in the various regions of the central nervous system (Glipin \& Koob, 2018). By inducing 
compromising mechanisms, continuous substance use creates short-term and lasting changes in neuronal function and makes neurotransmitters susceptible to fluids (Maldonado, 2018).

Among various factors associated with the tendency toward substance abuse, the role of emotional problems and the inability to control and regulate emotions are essential. People who are unable to regulate their emotions are more likely to use addictive substances (Waweru, Goodman, Kedenge, Tsofa, Molyneux. 2015). Therefore, substance abuse might act as a cognitive emotion regulation strategy to reduce their annoying emotional state (Ulrich-Lai, Fulton, Wilson, Petrovich, Rinaman, 2015). Cognitive emotion regulation is considered as processes through which people consciously and unconsciously balance their emotions to respond to environmental expectations (Bruggink, Huisman, Vuijk, Kraaij, Garnefski, 2016).

Cognitive emotion regulation is a purposeful process to influence the intensity, as well as the duration and type of emotion (Bryant \& Veroff, 2017). Several studies have suggested that difficulty in cognitive emotion regulation is related to a wide range of disorders, including substance abuse (Van der Kolk, 2017). Voon, Derbyshire, Rück, Irvine, Worbe, Enander, et al., (2015) have reported that people with emotional disturbances had higher scores in impulsivity, avoiding injury, and cognitive argument (Voon et al., 2015). Grant, Salsman, \& Berking (2018) have argued that poor cognitive regulation skills predict high alcohol consumption at post-treatment (Grant, Salsman, \& Berking, 2018). Substance abuse seriously harms individuals' health, family, financial status, security, and the cultural development of society. Therefore, substance dependence treatment has always been among the concerns of health policymakers and has been dedicated significant amounts of health financing (Waweru, Goodman, Kedenge, Tsofa, Molyneux. 2015).

Van Gordon, Shonin, Griffiths (2016), and Shorey, Elmquist, Gawrysiak, Anderson, Stuart (2016), reported a negative relationship between mindfulness and addictive behaviors. A study entitled "mindfulness-based relapse prevention on craving for drugs "has been conducted by Davis et al". They have explained that latent factors in admission and awareness scores have a mediating role in the significant relationship between receiving mindfulness and self-reporting craving levels after treatment. Moreover, the authorities experienced a wrong attitude in this therapeutic approach (Davis et al., 2017).
Substance dependence is among the significant dilemmas of societies, and its prevention and control seem necessary. In investigating factors associated with substance dependence, some important triggers are personality and psychological characteristics of individuals. Various studies suggested the effectiveness of mental treatments in the prevention and control of substance dependence. Therefore, the present study investigated the effect of MBCT on the intensity of substance dependence and emotion regulation in people undergoing Methadone Maintenance Treatment (MMT).

\section{Methods}

This was a quasi-experimental study with a Pre-testpost-test and a control group design. After the approval of research project by the Ethics Committee of the Kurdistan University of Medical Sciences, the relevant license was issued by Kamyaran City Health Center. All substance dependence clinics in Kamyaran County, Iran (6 clinics) were selected as the research community; among these, Hiva substance dependence treatment clinic was selected by purposive sampling method. The inclusion criteria were the presence of substance dependent patients in the relevant treatment clinic, and the lack of attending concurrent psychological treatments. Exclusion criteria were absence from more than two therapy sessions, unwillingness to continue treatment, the lack of methadone consumption, and being illiterate.

The moral considerations were observing the general guidelines of research ethics in the studies with human subjects, human dignity and human rights of each subject, the health and safety of each subject, acquiring informed consent of the study participants, and nonobligatory attendance to the treatment sessions. Of the patients treated in the Hiva clinic, 29 were selected with random sampling method. Moreover, 16 and 13 people were assigned into the control and experimental groups, respectively. The experimental group received 10 sessions (two sessions per week for 2 hours) of mindfulness therapy by Segal, Williams, \& Teasdale (2002). Using Cochran's formula, the sample size was determined as 135,30 for each group. In this formula, $\mathrm{P}$ and $\mathrm{q}=0.5$; $\mathrm{Z}=1.96$ and $\mathrm{d}=0.01$ or 0.05 . A summary of the sessions is presented in Table 1. The obtained data were analyzed using multivariate covariance method in SPSS.

The required data were collected using the following questionnaires: 
Table 1. A mindfulness-based cognitive intervention program

\begin{tabular}{|c|c|c|}
\hline & Session & Content \\
\hline 1 & Auto-guidance & $\begin{array}{l}\text { Communicate between group members; creating a therapy union; conducting the post-test; talking } \\
\text { about mindfulness and substance dependence; mindfully eating a raisin (a meditation in which study } \\
\text { participants spend a few minutes exploring the sensory-visual, olfactory, tasting, and touching of a rai- } \\
\text { sin). }\end{array}$ \\
\hline 2 & $\begin{array}{l}\text { Dealing with } \\
\text { barriers }\end{array}$ & $\begin{array}{l}\text { Practice thoughts and emotions (putting participants in a vague scenario like answering to not saying } \\
\text { hello of a friend on the street. Then, their reactions to such event and its impact are examined). Seated } \\
\text { meditation (a guided seated meditation of } 40-30 \text { minutes where the study participants are invited to } \\
\text { continue paying attention to their breathing pattern and curiously consider where their minds are wan- } \\
\text { dering; then, slowly return to focus on breathing. Eventually, emphasis will be extended to the body. }\end{array}$ \\
\hline 3 & $\begin{array}{l}\text { The presence of } \\
\text { mind and breathing } \\
\text { task }\end{array}$ & $\begin{array}{l}\text { Performing a 3-minute breathing (a 3-minute exercise in which the study participants first become aware } \\
\text { of the thoughts, emotions, and body senses of their present moment; then, they focus their attention } \\
\text { on breathing and ultimately extend their attention to the body as a whole). Visual meditation/hear- } \\
\text { ing meditation (a short meditative exercise where the study participants focus their attention on visual } \\
\text { sights or sounds and whenever their minds wander, they should slowly return to these senses). }\end{array}$ \\
\hline 4 & $\begin{array}{l}\text { Being in the } \\
\text { present time }\end{array}$ & $\begin{array}{l}\text { Seated meditation (attention is initially given to breathing; then, to the body. The study participants are } \\
\text { requested to explore their intense body feelings with an open and curious look). }\end{array}$ \\
\hline 5 & Permission & $\begin{array}{l}\text { Seated meditations (The study participants initially focus on breathing, physical sensations, and voices; } \\
\text { then concentrate on thoughts). Request to pay attention to mind wandering and if the mind is repeat- } \\
\text { edly returning to a particular thought, feeling or a certain sense of the body, to be curious about them, } \\
\text { searching for the difficulties that are created in their bodies during meditation, awareness of tension and } \\
\text { other ,complicated feelings, and using breathing as a means to keep the attention open. }\end{array}$ \\
\hline 6 & $\begin{array}{l}\text { Thoughts are } \\
\text { not facts }\end{array}$ & $\begin{array}{l}\text { Ambiguous scenarios. The study participants will be given another vague scenario, and requested to } \\
\text { search for their different reactions. } \\
\text { Home task: a 3-minute breathing, three times a day, and whenever there is a stress or complicated emo- } \\
\text { tion. Seated meditation (the awareness of breathing, body feelings, sounds, and thoughts). Referring to } \\
\text { the connection between creation and activity (the preparation of a list of activities and dividing those } \\
\text { into the activities that increase the level of energy and creativity and those which decline the mood and } \\
\text { are energy-consuming, and the use of these two categories of activity depending on the appearance of } \\
\text { mania or depression signs. }\end{array}$ \\
\hline 7 & Self-care & $\begin{array}{l}\text { Discussing relapse signs (The study participants are encouraged to talk about the signs of the recurrence } \\
\text { of their mania or depression; then, if these symptoms existed, what is their answer to those). }\end{array}$ \\
\hline 8 & Training & $\begin{array}{l}\text { Physical checkup. Homework task: experiences and answers on the exercises can change over time in } \\
\text { the light of new learning reflection (The study participants talk to each other about their initial intention } \\
\text { to participate in the classroom, what they have learnt, and possible obstacles to continue the exercise). } \\
\text { Feedback provision (receiving feedback from the study participants about their experiences in the class- } \\
\text { room. Conducting the post-test. }\end{array}$ \\
\hline
\end{tabular}

PRACTICE In
CLINICAL PSYCH $\odot$ LOGY

\section{Demographic information questionnaire}

The age, educational level, substance abuse status, substance use type, the age of substance abuse onset, the residency type (city/village), and marital status.

\section{Dependence Severity Index}

It consists of five items and it is a useful, quick, and easy instrument to evaluate the psychological aspects of the dependence on different drugs. This test evaluates the intensity of drug or alcohol dependence based on a 4-point Likert scale from "Never" (0) to "Always" (3) for the first four items and from "Not at all difficult" (0) to "Impossible" (3) for grade 5. The 5th grade scores are combined to calculate the overall score of this indicator. The range of points is from 0 to 15 and the score of 15 represents the highest level of dependency. Validity of this test through the internal consistency is 0.71 and the correlation coefficient between the pre-test and posttest was reported as 0.80 (McLellan, Kushner, Metzger, Peters, Smith, Grissom, 1992). Cronbach's alpha coefficient of this questionnaire has been reported to be $86 \%$ (Potthoff, Garnefski, Miklósi, Ubbiali, Domínguez-Sánchez, 2016).

\section{Cognitive Emotion Regulation Questionnaire}

This 36-item questionnaire measures cognitive emotion regulation strategies in response to threats and stressful life events using a 5-point Likert-type scale, based on 9 subscales. Every single item is scored from 1 (never) to 5 (always). The subscales of Cognitive Cognition Questionnaire are self-blame; acceptance; focus on thought; rumination; positive refocus; refocus on design; positive evaluation; underestimating; catastrophizing; and blaming others. The total score of each subscale is obtained by collecting the item scores; therefore, the scores for 
each subscale range between 4 and 20. High scores of each subscale indicate the extent to which this strategy is used more effectively in confronting and coping with stressful and adverse events (van Luenen, Kraaij, Spinhoven, \& Garnefski, 2016).

A general score is obtained by the total score of 36 items, which suggests the use of cognitive emotion regulation strategies, ranging from 36 to 180 points. In the preliminary study, the validation features of this questionnaire in a sample of the general population $(\mathrm{N}=365$; 197 women and 171 men), Cronbach's alpha coefficients for subscales were calculated from 0.70 to 0.89 . Moreover, these coefficients were significant at $\mathrm{P}<0.001$. The internal consistency of the cognitive emotion regulation questionnaire is reported. The test-retest reliability for the subscales of this questionnaire was reported to be 0.57 to 0.76 in two intervals of 2-4 weeks. In addition, its content validity was reported based on 8 psychologists; the Kendall consensus coefficients for the subscales were 0.81 to 0.92 (Kesbakhi, Rohani, Mohtashami, Nasiri, 2017). Yousefi and Carranza (2015) evaluated the validity and reliability of this scale in Iranian adolescents. Reliability coefficient in the form of Cronbach's coefficient for negative emotion regulation strategies was calculated equal to 0.78 , the same score for the subscales of positive emotion regulation strategies was 0.83 , the total scale score was 0.81 , and scale validity coefficient was reported to be 0.85 (Kesbakhi, Rohani, Mohtashami, Nasiri, 2017).

\section{Results}

Table 2 presents the Mean \pm SD scores of the experimental and control groups as follows: age: $31.27 \pm 3.61,35.87 \pm 2.23$ years; single marital status: $40.21 \pm 3.08,59.78 \pm 3.33$ ), married marital status: $33.11 \pm 4.00,66.89 \pm 3.87$, the age of substance abuse onset: $23.54 \pm 3.14,26.33 \pm 3.01$ years, the duration of use: $4.11 \pm 2.46,6.03 \pm 3.22$ years, respectively; regarding the type of use (experimental group: 3 people used opium, 4 used methamphetamine, 5 used tramadol, 4 used heroin; and in the control group: 5 used opium, 3 used methamphetamine, 3 used tramadol, and 2 used heroin); the educational level in the experimental group: 10 had high-school degree, 3 had diploma, 2 had graduate degree, 3 had bachelor's degree; in the control group, 9 had high-school degree, 3 had diploma, and 1 had graduate degree; the residence place: in the experimental group, 7 subjects lived in a village, 9 in a city, and in the control group, 5 subjects lived in a village, and 8 in a city.

Table 2 lists the Mean \pm SD scores of the intensity of substance dependence, negative cognitive emotion regulation, and positive cognitive emotion regulation for the experimental and control groups. Multivariate covariance analysis was used to investigate the effectiveness of MBCT; one of the assumptions of this analysis is equality of error variances. Levene's test results are presented to examine this assumption.

Table 2. Mean \pm SD scores of variables in the experimental and control groups

\begin{tabular}{cccc}
\hline Variables & Group & Mean \pm SD \\
\hline $\begin{array}{c}\text { The intensity of } \\
\text { substance dependence }\end{array}$ & Experimental & $13.43 \pm 1.72$ & $8.60 \pm 2.26$ \\
$\begin{array}{c}\text { Negative cognitive } \\
\text { emotion regulation }\end{array}$ & Control & $21.87 \pm 1.55$ & $8.20 \pm 2.56$ \\
$\begin{array}{c}\text { Positive cognitive } \\
\text { emotion regulation }\end{array}$ & Control & $42.66 \pm 13.44$ & $59.13 \pm 12.35$ \\
& Experimental & $47.60 \pm 6.62$ & $52.00 \pm 9.18$ \\
\hline & Control & $37.15 \pm 3.14$ & $49.53 \pm 9.88$ \\
& & $59.45 \pm 7.64$ & $55.60 \pm 12.70$ \\
\hline
\end{tabular}

Table 3. Levene's test for examining the equality of error variances

\begin{tabular}{|c|c|c|c|}
\hline Variables & $\mathbf{F}$ & df & $\mathbf{P}$ \\
\hline Intensity of substance dependence & 2.33 & 25 & 0.29 \\
\hline Emotion regulation & 0.545 & 25 & 0.45 \\
\hline
\end{tabular}


Table 4. The results of multivariate covariance analysis in respect of the patterns of difference

\begin{tabular}{|c|c|c|c|c|c|}
\hline Variables & Sum of Squares & df & Mean Squares & $\mathbf{F}$ & $\mathbf{P}$ \\
\hline The intensity of substance dependence & 14.38 & 1 & 14.38 & 2.34 & 0.045 \\
\hline Negative cognitive emotion regulation & 487 & 1 & 487 & 16.24 & 0.001 \\
\hline Positive cognitive emotion regulation & 795.547 & 1 & 795.547 & 15.28 & 0.001 \\
\hline
\end{tabular}

As per Table 3, the homogeneity assumption of error variances is equal in all variables $(\mathrm{P}<0.05)$. Box's test was used to examine the assumption of equality of variance-covariance matrix. The obtained results suggested that this assumption is valid $(\mathrm{P}=0.05, \mathrm{~m}=5.33)$. Moreover, the Kolmogorov-Smirnov test results indicated that the distribution of variables was normal in both groups $(\mathrm{P} \leq 0.05)$. Wilks' Lambda test results indicated a significant difference in the linear combination of variables between the two groups (Wilks' Lambda:0.28, $\mathrm{F}=160.13, \mathrm{P} \leq 0.001)$. Therefore, the use of multivariate covariance analysis is permissible, and its analysis is presented in Table 4.

As per Table 4, there was a significant difference between the experimental and control groups in terms of the intensity of substance dependence. Moreover, MBCT created a significant difference in the positive and negative cognitive settings.

\section{Discussion}

The current research aimed to examine the effectiveness of MBCT on reducing the intensity of substance dependence and emotion regulation. The obtained data suggested that MBCT reduced the severity of substance dependence in the experimental group, compared to the controls. These findings are consistent with those of Grensman et al., (2018), Segal ZV \& Teasdale (2018), van der Velden (2015), Cairncross \& Miller (2016), Herman et al., (2017), Shulman et al., (2018), and Spijkerman, Pots, \& Bohlmeijer (2016).

In explaining the above-mentioned findings, mindfulness is a method that humans use to save themselves from the daily living sufferings and pains (Grensman et al., 2018). Therefore, mindfulness and act in the present time moderate the effect of bio-emotional sensitivities caused by substance abuse on apparent behavior through the person's relationship with these experiences. In MBCT, substance dependent patients are trained to accept and tolerate their experiences to the point they can and they are told that to the same extent they can act independently of the experience (Shulman et al., 2018). Teaching assignments, including functional analysis and coping with consumption desire generate the feeling of mastery and capability in these individuals; this increases their motivation for treatment or at least the continuation of treatment, and avoiding high-risk behaviors (Segal \& Teasdale, 2018). The present study also revealed that MBCT increases the use of cognitive regulation strategies and reduces the use of negative emotional regulation strategies in people undergoing MMT. These results are in line with those of Schmidt et al., (2018), Garnefski, Hossain, \& Kraaij, (2017).

Academic interest in cognitive and emotional components suggested mindfulness as an effective technique. Schmidt et al., (2018) suggested the model of three principles of mindfulness, including intention, attention, and attitude. Intention refers to the intentional or motivational aspects of the mindfulness. Attention refers to the mindfulness and observing the current experience. Attitude refers to non-judgmental behaviors and accepting experiences. They believe that the mindfulness involves a variety of psychological mechanisms which reduce distress. These mechanisms are rethinking or reformatting experiences from a better metacognitive perspective, improving emotions, selfregulation, increasing mental flexibility, and desensitizing empathic experiences through the perceived lack of threat (Garnefski et al., 2017). It is likely that these new emotional and cognitive aspects be a neuroscience framework, through which the mindfulness is related to substance abuse (Garnefski et al., 2017).

In the relationship between mindfulness and cognitive emotion regulation, the emphasis is on accepting the non-judgmental nature of thoughts and emotions as the core of mindfulness (Schmidt et al., 2018). Those who practice mindfulness, learn to intentionally observe their emotional states and accept that it will enable them to reduce habitual tendencies and habits, observable in the form of rumination (Brockman, Ciarrochi, Parker, Kashdan, 2017). It also enhances the processing of more informative emotional information (Opialla et al., 
2015). Mindfulness can help to observe and accept the emotions and physical phenomena as they occur. This process is done through increasing one's awareness of the biopsychological feelings, leading to the ordering of such emotions (Schmidt et al., 2018). MBCT assists a group of people to learn to cope with their negative thoughts and emotions and experience mental events positively (Strauss, Kivity, Huppert, 2019).

The main element of MBCT is fundamental mindfulness. Fundamental mindfulness is based on the adoption of unpleasant thoughts and different emotional states. It increases the ability of an individual to dramatically control the influence of their thoughts and emotions. It also allows people to experience a wide range of thoughts and emotions without emotional turmoil in mind (Allard \& Kensinger, 2018).

According to the obtained results, MBCT can effectively reduce substance dependence and improve cognitive emotion regulation in people undergoing MMT. Thus, by training these skills, a practical step can be taken to treat this population. The limitations of this research were the impossibility of generalizing the results to females undergoing MMT, and the lack of a follow-up stage. It is suggested to conduct further research using this therapeutic approach for both genders through controlling substance use and follow-up phases.

\section{Ethical Considerations}

\section{Compliance with ethical guidelines}

All the ethics of txhis research were approved by the Ethics Committee of Kurdistan University of Medical Sciences. (Code of Ethics: IR.MUK.REC.1396/232).

\section{Funding}

The Deputy of Research and Technology of Kurdistan University of Medical Sciences has sponsored the project.

\section{Authors' contributions}

Conceptualization: Shokoufeh Ramezani, Abdul Rahim Afkhamzadeh, Hassan Qorbani; Methodology, Software, Validation, Formal analysis: Shokoufeh Ramezani, Abdul Rahim Afkhamzadeh, Saifullah Rahmani; Investigation, Resources, Data curation, Writing-original draft preparation, Writing-review \& editing: Shokoufeh Ramezani, Abdul Rahim Afkhamzadeh; Visualization, Supervision, Project administration, Funding acquisition: Shokoufeh Ramezani, Abdul Rahim Afkhamzadeh, Salm Naimi.

\section{Conflict of interest}

The authors declared no conflict of interest.

\section{Acknowledgments}

All authors thank the Deputy of Research and Technology of Kurdistan University of Medical Sciences.

\section{References}

Allard, E. S., \& Kensinger, E. A. (2018). Cognitive emotion regulation in adulthood and old age: Positive gaze preferences across two strategies. Aging, Neuropsychology, and Cognition, 25(2), 213-30. [DOI:10.1080/13825585.2017.1279265] [PMID]

Brockman, R., Ciarrochi, J., Parker, P., \& Kashdan, T. (2017) Emotion regulation strategies in daily life: Mindfulness, $\operatorname{cog}$ nitive reappraisal and emotion suppression. Cognitive Behaviour Therapy, 46(2), 91-113. [DOI:10.1080/16506073.2016.12189 26] [PMID]

Bruggink, A., Huisman, S., Vuijk, R., Kraaij, V., \& Garnefski, N. (2016). Cognitive emotion regulation, anxiety and depression in adults with autism spectrum disorder. Research in Autism Spectrum Disorders, 22,34-44. [DOI:10.1016/j.rasd.2015.11.003]

Bryant, F. B., \& Veroff, J. (2017). Savoring: A new model of positive experience. London: Psychology Press. [DOI:10.4324/ 9781315088426]

Cairncross, M., \& Miller, C. J. (2016). The effectiveness of mindfulness-based therapies for ADHD: A meta-analytic review. Journal of attention disorders, 1087054715625301.

Davis, J. P., Berry, D., Dumas, T. M., Ritter, E., Smith, D. C., Menard, C., et al., (2018). Substance use outcomes for mindfulness based relapse prevention are partially mediated by reductions in stress: Results from a randomized trial. Jour nal of Substance Abuse Treatment, 91, 37-48. [DOI:10.1016/j. jsat.2018.05.002] [PMID]

Garnefski, N., Hossain, S., \& Kraaij, V. (2017). Relationships between maladaptive cognitive emotion regulation strategies and psychopathology in adolescents from Bangladesh. Archives of Depression and Anxiety, 3(2), 23-9.

Gilpin, N. W., \& Koob, G. F. (2008). Neurobiology of alcohol dependence: Focus on motivational mechanisms. Alcohol Re search \& Health, 31(3), 185-95. [PMID] [PMCID]

Grant, M., Salsman, N. L., \& Berking, M. (2018). The assessment of successful emotion regulation skills use: Development and validation of an English version of the Emotion Regulation Skills Questionnaire. PLOS One, 13(10), e0205095. [DOI:10.1371/journal.pone.0205095] [PMID] [PMCID]

Green, T. C., Clarke, J., Brinkley-Rubinstein, L., Marshall, B. D. Alexander-Scott, N., Boss, R., et al., (2018). Postincarceration fatal overdoses after implementing medications for addic- 
tion treatment in a statewide correctional system. JAMA Psychiatry, 75(4), 405-7. [DOI:10.1001/jamapsychiatry.2017.4614] [PMID] [PMCID]

Grensman, A., Acharya, B. D., Wändell, P., Nilsson, G. H., Falkenberg, T., Sundin, Ö., et al., (2018). Effect of traditional yoga, mindfulness-based cognitive therapy, and cognitive behavioral therapy, on health related quality of life: A randomized controlled trial on patients on sick leave because of burnout. BMC Complementary and Alternative Medicine, 18, 80. [DOI:10.1186/s12906-018-2141-9] [PMID] [PMCID]

Herman, P. M., Anderson, M. L., Sherman, K. J., Balderson, B. H., Turner, J. A., \& Cherkin, D. C. (2017). Cost-effectiveness of Mindfulness-based stress reduction versus cognitive behavioral therapy or usual care among adults with chronic low back pain. Spine, 42(20), 1511-20. [DOI:10.1097/ BRS.0000000000002344] [PMID] [PMCID]

Garland, D. (2012). Punishment and modern society: A study in social theory. Chicago, Illinois, United States: University of Chicago Press.

Kesbakhi, M. S., Rohani, C., Mohtashami, J., \& Nasiri, M. (2017). Empathy from the perspective of oncology nurses. Journal of Compassionate Health Care, 4(1), 7.

Kingston, T., Dooley, B., Bates, A., Lawlor, E., \& Malone, K. (2007). Mindfulness-based cognitive therapy for residual depressive symptoms. Psychology and Psychotherapy: Theory, research and practice, 80(2), 193-203.

Maldonado, J. R. (2018). Delirium pathophysiology: An updated hypothesis of the etiology of acute brain failure. International Journal of Geriatric Psychiatry, 33(11), 1428-57. [DOI:10.1002/ gps.4823] [PMID]

Marchiafava, M., Piccirilli, M., Bedetti, C., Baglioni, A., Menna, M., \& Elisei, S. (2018). Effectiveness of serotonergic drugs in the management of problem behaviors in patients with neurodevelopmental disorders. Psychiatria Danubina, 30(Suppl 7) 644-7. [PMID]

McEvoy, P. M., Graville, R., Hayes, S., Kane, R. T., \& Foster, J. K. (2017). Mechanisms of change during attention training and mindfulness in high trait-anxious individuals: A randomized controlled study. Behavior Therapy, 48(5), 678-94. [DOI:10.1016/j.beth.2017.04.001] [PMID]

McLellan, A. T., Kushner, H., Metzger, D., Peters, R., Smith, I., Grissom, G., et al., (1992). The fifth edition of the addiction severity index. Journal of Substance Abuse Treatment, 9(3), 199213. [DOI:10.1016/0740-5472(92)90062-S]

Opialla, S., Lutz, J., Scherpiet, S., Hittmeyer, A., Jäncke, L., Rufer, M., et al., (2015). Neural circuits of emotion regulation: A comparison of mindfulness-based and cognitive reappraisal strategies. European Archives of Psychiatry and Clinical Neuroscience, 265(1), 45-55. [DOI:10.1007/s00406-014-0510-z] [PMID]

Potthoff, S., Garnefski, N., Miklósi, M., Ubbiali, A., \& Domínguez-Sánchez, F. J., et al., (2016). Cognitive emotion regulation and psychopathology across cultures: A comparison between six European countries. Personality and Individual Differences, 98, 218-224.

Schmidt, L., Tusche, A., Manoharan, N., Hutcherson, C., Hare, T., \& Plassmann, H. (2018). Neuroanatomy of the vmPFC and dIPFC predicts individual differences in cognitive regulation during dietary self-control across regulation strategies. Jour- nal of Neuroscience, 38(25), 5799-06. [DOI:10.1523/JNEURON SCI.3402-17.2018] [PMID] [PMCID]

Segal, Z. V., \& Teasdale, J. (2018). Mindfulness-based cognitive therapy for depression. New York: Guilford Publications.

Segal, Z. V., Williams, J. M. G., \& Teasdale, J. D. (2002). Mindfulness-based cognitive therapy for depression: A new approach to preventing relapse. New York: Guilford Press.

Shulman, B., Dueck, R., Ryan, D., Breau, G., Sadowski, I., \& Misri, S. (2018). Feasibility of a mindfulness-based cognitive therapy group intervention as an adjunctive treatment for postpartum depression and anxiety. Journal of Affective Disorders, 235, 61-7. [DOI:10.1016/j.jad.2017.12.065] [PMID]

Shorey, R. C., Elmquist, J., Wolford-Clevenger, C., Gawrysiak, M. J., Anderson, S., \& Stuart, G. L. (2016). The relationship between dispositional mindfulness, borderline personality features, and suicidal ideation in a sample of women in residential substance use treatment. Psychiatry research, 238, 122-128.

Spijkerman, M. P. J., Pots, W. T. M., \& Bohlmeijer, E. T. (2016). Effectiveness of online mindfulness-based interventions in improving mental health: A review and meta-analysis of randomised controlled trials. Clinical Psychology Review, 45, 102 14. [DOI:10.1016/j.cpr.2016.03.009] [PMID]

Strauss, A. Y., Kivity, Y., \& Huppert, J. D. Emotion regulation strategies in cognitive behavioral therapy for panic disorder. Behavior Therapy, 50(3):659-71. [DOI:10.1016/j. beth.2018.10.005] [PMID]

Stroes, E. S., Thompson, P. D., Corsini, A., Vladutiu, G. D. Raal, F. J., \& Ray, K. K., et al., (2015). Statin-associated muscle symptoms: Impact on statin therapy- European Atherosclerosis Society consensus panel statement on assessment, aetiology and management. European Heart Journal, 36(17), 1012-22. [DOI:10.1093/eurheartj/ehv043] [PMID] [PMCID]

Ulrich-Lai, Y. M., Fulton, S., Wilson, M., Petrovich, G., \& Rinaman, L. (2015). Stress exposure, food intake and emotional state. Stress, 18(4), 381-99.

Van der Kolk, B. A. (2017). Developmental trauma disorder: Toward a rational diagnosis for children with complex trauma histories. Psychiatric Annals, 35(5), 401-8. [DOI:10.3928/00485713-20050501-06]

van der Velden, A. M., Kuyken, W., Wattar, U., Crane, C., Pallesen, K. J., Dahlgaard, J., et al., (2015). A systematic review of mechanisms of change in mindfulness-based cognitive therapy in the treatment of recurrent major depressive disorder. Clinical Psychology Review, 37, 26-39. [DOI:10.1016/j. cpr.2015.02.001] [PMID]

Van Gordon, W., Shonin, E., \& Griffiths, M. D. (2016). Meditation awareness training for the treatment of sex addiction A case study. Journal of Behavioral Addictions, 5(2), 363-72. [DOI:10.1556/2006.5.2016.034] [PMID] [PMCID]

Van Luenen, S., Kraaij, V., Spinhoven, P., \& Garnefski, N. (2016). An internet-based self-help intervention for people with hiv and depressive symptoms: Study protocol for a randomized controlled trial. Trials, 17, 172. [DOI:10.1186/s13063-016-12926] [PMID] [PMCID]

Voon, V., Derbyshire, K., Rück, C., Irvine, M. A., Worbe, Y., \& Enander, J., et al., (2015). Disorders of compulsivity: A common bias towards learning habits. Molecular Psychiatry, 20(3), 345. 
Wallace, B. C. (2019). Making mandated addiction treatment work. Maryland: Rowman \& Littlefield.

Waweru, E., Goodman, C., Kedenge, S., Tsofa, B., \& Molyneux, S. (2015). Tracking implementation and (un) intended consequences: A process evaluation of an innovative peripheral health facility financing mechanism in Kenya. Health Policy and Planning, 31(2), 137-47. [DOI:10.1093/heapol/czv030] [PMID] [PMCID]

Yousefi, M., \& Carranza, E. J. M. (2015). Prediction-area (P-A) plot and C-A fractal analysis to classify and evaluate evidential maps for mineral prospectivity modeling. Computers $\mathcal{E}$ Geosciences, 79, 69-81.

Cairncross, M., \& Miller, C. J. (2016). The effectiveness of mindfulness-based therapies for ADHD: a meta-analytic review. Journal of Attention Disorders, 1087054715625301. 
This Page Intentionally Left Blank 